\title{
Cerebral Vein Thrombosis Post Cabg Precipitated by Malposition of Subclavian Central Catheter in Protein C \& S Deficiency Patient
}

\author{
Feridoun Sabzi ${ }^{1}$, Reza Faraji ${ }^{2}$
}

\begin{abstract}
BACKGROUND: Cerebral venous thrombosis is an uncommon disorder in the general population. However, it has a higher frequency among patients younger than 40 years, patients with thrombophilia and patients that have foreign body such as catheter in their veins or arterial system.

CASE DETAILS: In this case report, we described the clinical and radiological findings of a patient who developed cerebral vein thrombosis post coronary artery bypass grafting secondary undiagnosed protein $C$ and $S$ deficiency which was precipitated by malposition of subclavian central catheter into internal jugular vein.

CONCLUSION: We emphasis the importance of radiological veiw of central vein catheter position just after or at the time of cannulation of central vein, not at some hours later as in our case. Keywords: thrombosis, cerebral veins, thrombophilia
\end{abstract}

DOI: http://dx.doi.org/10.4314/ejhs.v25i3.13

\section{INTRODUCTION}

Central venous catheterization (CVC) via subclavian approach is a very common practice in cardiac surgery, in the view of simplicity, monitoring of blood volume, monitoring of cardiac status, vasomotor tone, management of prolonged surgery and rapid compensation of blood loss intra operatively or in post operative courses. Langston et al. (1) found that the most common malposition related to subclavian vein catheterization is entrance into the internal jugular vein. Malposition of a CVP line in the jugular vein automatically has not any complication in the absence of hypercoagulable state. Family histories or history of thromboembolism and an unusual site of thrombosis are emphasized for accurate diagnosis of thrombophilia in the post surgery state. However, the post surgical state could be considered as a hypercoagulable state in the absence of reduced serum level of protein C-S. Although, there are some reports of JVT with extension to a subclavein vein or the right atrium and subsequent pulmonary artery emboli, but retrograde progression of thrombus from catheter site in jugular vein to cerebral venous system has not been reported in the medical literature $(2,3,4)$. Herein, we report a patient who developed cerebral vein thrombosis in post CABG secondary to undiagnosed protein $\mathrm{C}$ and $\mathrm{S}$ deficiency which was precipitated by malposition of subclavian central catheter into IJV.

\section{CASE REPORT}

A 38 years old, $80 \mathrm{~kg}$ male patient with history of thrombophelebitis presented with left main coronary artery disease on angiocardiography. Neurological examination was be normal and the patient did not have any signs and symptoms such as headache, lethargy, motor or sensory deficits, seizures, neck stiffness and fever. Peripheral arterial pulses were palpable in all extremity areas.

\footnotetext{
${ }^{1}$ Preventive Cardiovascular Research Centre Kermanshah, Kermanshah University of Medical Sciences, Kermanshah, Iran.

${ }^{2}$ Yazd Cardiovascular Research Center, Shahid Sadoughi University of Medical Sciences, Yazd, Iran

Corresponding Author: Reza Faraji, Email: r.faraji61@gmail.com
} 
Cervical murmur was noted with carotid auscultation, and the remainder of the physical examination was normal.There was no evidence suggestive of thrombus in the left ventricle.The patient was scheduled for Off-pump coronary artery bypass grafting (OPCAB) with general anesthesia, central venous pressure (CVP) line and arterial monitoring. A (CVP) line was inserted via the right subclavian vein by Seldinger technique (3) under aseptic precautions by the anesthesia registrar in the operating room. Passage of the catheter was smooth and unimpeded. There was a good CVP waveform and good back flow of blood on aspiration from all the three lumens. Anesthesia protocol included a combination of fentanyl and pancronium bromide supplemented with isoflurane to permit early extubation. OPCAB was performed through a sternotomy incision. Stabilization of target arteries was accomplished with octopus stabilizer (Medtronic, Ts 300). Intravenous heparin $(1 \mathrm{mg} / \mathrm{kg})$ was given to maintain activated clotting time (ACT) between 200 and 300 seconds. After surgery, the patient was admitted to the ICU. CVP readings were taken $30 \mathrm{~min}$ apart and each time a good back flow was noted. As part of routine protocol, a portable chest X-ray was performed next morning (12 hours) and, the CVP catheter was found to be internally rotated inside the right proximal internal jugular vein in the direction to cavernous sinus. The shoulder radiography confirmed its malposition. The line was settled in mid part of IJV (Figure 1). However, blood could be aspirated from all the three lumen ports, CVP was measured with a normal CVP wave form and IV fluids/drugs could be infused via the same catheter; we intended to pullout the line and re route it to right atrium. In ICU, the patient was noted to be hemodynamically stable. Despite normal pupil examination, he did not have the normal extremity movement or related awakening of the cerebral functions or spontaneous eye opening. The antibrains edema therapy with steroid was started but the cerebral pathology was seen to persist at the fifth day of post operation. Despite neurologist recommendation, the respiratory instability did not permit to transfer the patient for brain imaging safely. The patient's neurological status improved with medication gradually. However early extubation failed on the eight postoperative day, but the patient was able to move his limbs although he was drowsy. On the twelve postoperative day, he opened his eyes and was able to obey commands; however, he was not able to move his left arm. The patient was extubated on the $15^{\text {th }}$ day of operation. History of thrombophelebitis, young age, sub-acute presentation, focal neurologic sign and its rapid recovery urged to reconsider a MRI venography and thrombophilia test for detection of cerebral veins pathology. Complete blood count and blood biochemistry were within normal limits, except for prolonged erythrocyte sedimentation and areduced protein $\mathrm{C}$ and $\mathrm{S}$ level. The protein $\mathrm{C}$ level was $35 \%$ (normal: > 70), and protein $\mathrm{S}$ level was $55 \%$ (normal: 65\%). There were no abnormal values of antithrombin III, lupus anticoagulant, and anticardiolipin antibodies. The other tests such as HLA-B5, HLA-B27, anti-nuclear antibody and rheumatoid factor were also negative. Three months follow-up revealed reduced protein C-S levels. MRI venoghraphy on the $18^{\text {th }}$ day of hospital stay revealed thrombosis of cerebral dural vein with typical delta sign, effacement of brains sulcui and edema, but infarction or hemorrhage was not observed (Figures 2,3). Further course of the patient in the hospital was uneventful.



Figure 1: Central vein cathter going up to cerebral vein 


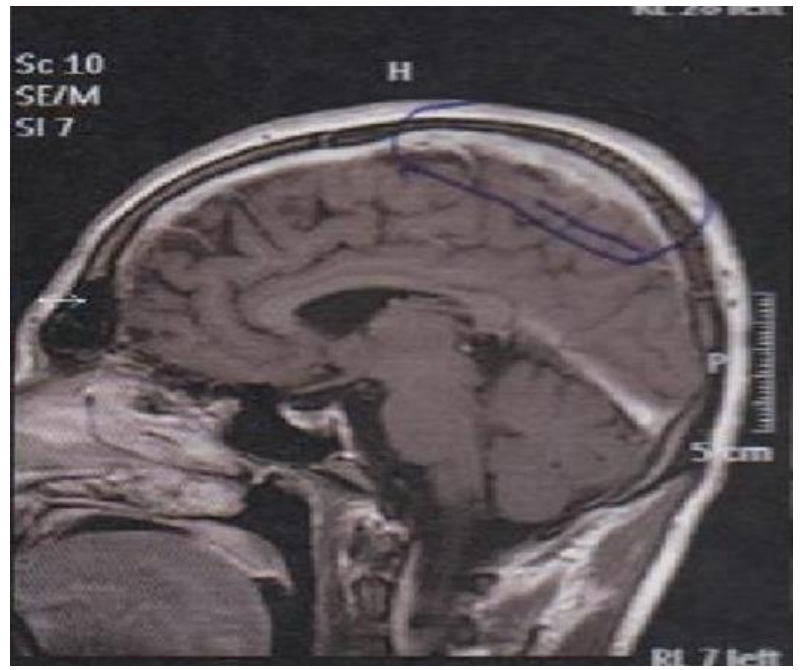

Figure 2: Magneticresonance imaging showing Duralvein thrombosis

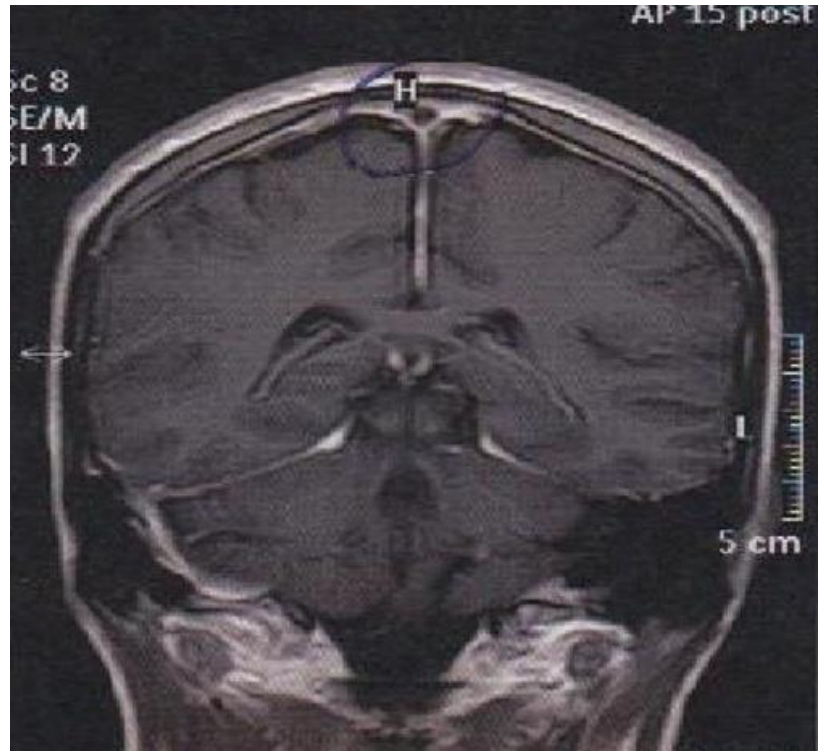

Figure 3: Magnetic resonance imaging revealing empty delta sign

\section{DISCUSSION}

Protein C-S is a vitamin K-dependent, serine protease that is found in the blood plasma and synthesized in the liver. The active form of protein C-S can inhibit blood coagulation and stimulate fibrinolysis (1). SVT has been often a multi factorial disease, i.e the identification of a risk factor or even of a cause should not deter a search for other causes $(5,6)$. Several studies, have described some of the well-established risk factors for SVT that include inherited thrombophilia such as factor $\mathrm{V}$ Leiden mutation, protein $\mathrm{C}$ and $\mathrm{S}$ deficiency, acquired prothrombotic state (pregnancy, purperium and postsurgical period), hepatic dysfunction ,autoimmune disease (Behçet syndrome, systemic lupus erythematosus), malignancy (lung cancer, blood dyscrasia, systemic carcinoma), systemic infectious disease, local infection of the skull (e.g. otitis, mastoiditis) and use of oral contraceptives. Other rare conditions predisposed to SVT include, inflammatory bowel disease, spontaneous intracranial hypotension, demyelinating disease, Down's Syndrome, idiopathic hypereosinophilic syndrome, Evans syndrome (immune thrombocytopenia and autoimmune hemolytic anemia), bone marrow transplantation, high altitude, trivial trauma, jumping from a rock, surgical procedures, head trauma, brain tumors and arterial infarcts (7-14). Nagesh Kumar reported a case of a 35 years old male who presented to the emergency center with drowsiness and focal seizures leading to grand seizures and loss of consciousness. There was no past history of seizures or other medical co-morbidities. There was no family history of seizures or other illnesses. Lab examination revealed protein $\mathrm{S}$ deficiency (15). Marcos reported a 22-year-old woman with AIDS who presented with altered consciences. A brain MRI and angiogram showed sagittal sinus thrombosis. Significantly low protein S (7\%; normal $54-137 \%)$ and C (41\%; normal 72$147 \%$ ) levels were detected. No other hypercoagulable factors were identified. The author concluded that advanced AIDS might be considered as an acquired hypercoagulable state (16). Kuwahara described a 47 years old male who, despite anticoagulant therapy for thrombophlebitis for long time period, presented with mild left hemiparesis and ipsilateral hypesthesia. Magnetic resonance (MR) imaging showed subacute thrombosis of both SVT and a cortical vein in the right cerebral hemisphere. The diagnosis was SVT and cerebral cortical venous thrombosis caused by congenital protein $\mathrm{C}$ deficiency. The patient was treated conservatively, and his clinical course was uneventful (17). Singhal reported a case of hepatic failure caused thrombophilia by severe deficiency of protein $\mathrm{C}$, protein $\mathrm{S}$ and antithrombin III. Thrombophilia caused SVT. Recurrent seizures were the only manifestation (18). Lefebvre presented the combined occurrence of protein $\mathrm{C}$ and protein $\mathrm{S}$ 
deficiencies in a 32 years old woman who presented by focal neurological sign and symptom and manifested by extensive cerebral venous thrombosis (19). Roos described a case of intracranial dural sinus thrombosis in the postpartum period related to the hypercoagulable state of pregnancy. The author report a patient who developed a superior sagittal sinus thrombosis in the second week postpartum, associated with a dysfunctional protein $\mathrm{C}$ and a decreased free protein $S$ concentration (20). Massons reported a 32 years old patient with protein $\mathrm{C}$ deficiency who presented with the endocranial hypertension syndrome and multiple hemorrhagic cerebral infarction. Arteriography confirmed vertebral venous thrombosis. The author demonstrated the importance of considering protein $\mathrm{C}$ deficiency in the diagnosis of cerebral venous thrombosis in young adults (21). Chung evaluated Central venous catheter (CVC) blockage as a complication in pediatric oncology patients. This author investigated inherited thrombophilic states as a predisposing factors for CVC blockage in Chinese children with cancer. The author concluded that inherited thrombophilic factors alone were not associated with CVC blockage in their,s pediatric cancer patient population (22). Barker reviewed his cytic fibrosis center's history of catheter-related events over 13 years and found five thrombotic events in four patients, two of whom carried the factor $\mathrm{V}$ Leiden mutation. The author concluded that thrombophilic state was detected in 53\% patients, and two out of four subjects with catheter related thrombosis carried a genetic defect. No patient had protein C-S deficiency (23). Nowak determined the association between catheter-related thromboses and hereditary causes of thrombophilia. Protein C deficiency was diagnosed in nine subjects. The author concluded that genetic risk factors for familial thrombophilia play an important role in the manifestation of catheter-related thromboembolism in children (24). Wermes evaluated the clinical relevance of genetic risk factors of thrombosis in 137 paediatric patients with malignancy. All patients had central venous lines. No patient received heparin or any other anticoagulant. Ten patients (7.3\%), six with leukemia and four with solid tumors developed thrombosis. Four of the six patients with leukemia and thrombosis $(67 \%)$ but only $21 \%$ of leukemia patients without thrombosis had a genetic risk factor $(\mathrm{P}<0.013$, chi2). No genetic defect was found in the four patients with other solid malignancies and thrombosis (25). A prothrombotic risk factor or a direct cause is identified in about $85 \%$ of the patients with sinus thrombosis. Often, a precipitating factor such as foreign body in venous system like CVP line, head injury or even surgical immobility causes sinus thrombosis in a person with a genetically increased risk such as thrombophilia state. Our case had predisposing risk factors for SVT such as history of DVT, post surgical period and mal position of CVP line, but CABG was performed by beating heart and without use of $\mathrm{CPB}$ or fibrinolytic drugs as predisposing factors to thrombosis. Post-surgical state automatically did not predispose to SVT in the absence of thrombophilia. Some cases of SVT in the pregnancy related surgical procedures were associated with hyper coagulable state and hormonal change of pregnancy. In our patient, central line was exactly malpositioned into the internal jugular vein. In non-thrombophilic patients, risk of thromboembolic sequels in temporary CVP malposition is probably very low, but in thrombophilic disorders such as protein c-s deficiency, this risk severely increased. Ferro fund that at least one risk factor such as internal jugular vein cathterizem can be identified in more than $85 \%$ of patients with cerebral venous thrombosis and an aquired thrombophilia and inherited thrombophilia was noted in $34 \%, 22 \%$ of patients subsequently (26). Inherited thrombophilias associated with cerebral venous thrombosis with or without foreign body include deficiencies of antithrombin, protein $\mathrm{C}-\mathrm{S}$ deficency, factor $\mathrm{V}$ Leiden mutation and the prothrombin gene mutation 20210 (27). Antiphospholipid antibodies and hyper homocysteinemia are acquired prothrombotic states associated with cerebral venous thrombosis. The most probable explanation of SVT in our patient with unusual course of CVP line in the jugular vein in proximity to cerebral veins was the presence of a background of protein C-S deficiency. Brain imaging sually has a key role in the diagnosis of CVT. Angiography, magnetic resonance (MR) imaging, un-enhanced computed tomography (CT), MR venography and CT venography are particularly useful techniques for detecting 
cerebral venous and brain parenchymal changes that may be related to thrombosis. CVT may cause obstruction of venous drainage with increasing venous pressure in the affected region of the brain and causes parenchyma changes, secondary to cytotoxic edema, vasogenic edema, or intracranial hemorrhage. In contrast with arterial ischemic states, many parenchymal abnormalities secondary to venous occlusion are reversible. The direct signs of SVT include demonstration of the thrombus on imaging or indirect, as when there are ischemic or vascular changes related to the venous outflow disturbance. Indirect signs are not specific, such as parenchyma change by brain swelling, white matter edema, cortical sulci narrowing, loss of gray-white matter differentiation and hemorrhagic infarction as hemorrhagic spot in white matter edema (27.28). In conclusion, this case report aims to bring to attention the possibility of sagittal vein thrombosis associated with malposition and internal rotation of CVP line inside vessels in thrombophilic patient. This complication hitherto reported only in children with CVP line inserted for malignancy. More than half of these patients had thrombophilia. Careful literature search revealed that our case is the only reported case of thrombophilia induced SVT predisposed by CVP line. We reiterate the importance of radiological verification of CVP catheter position just after or at the time of cannulation of central line, not at 12 hour later as in our case.

\section{REFERENCES}

1. Langston CS. The aberrant central venous catheter and its complications. Radiology 1971;100:55-59.

doi: http://dx.doi.org/10.1148/100.1.55

2. Ducatman B, McMichan J, Edwards W. Catheter-induced lesions of the right side of the heart. A one-year prospective study of 141 autopsies. JAMA 1985;253:791-5. doi:10.1001/jama.1985.03350300079024.

3. Pikwer A, Bååth L, Davidson B, Perstoft I, Akeson J. The incidence and risk of central venous catheter malpositioning: A prospective cohort study in 1619 patients. Anaesth Intensive Care 2008;36:30-7.

4. Seldinger SI. Catheter replacement of the needle in percutaneous arteriography: a new technique. Acta Radiol 1953;39:368-76.
5. Marlar RA, Mastovich S. Hereditary protein C deficiency: a review of the genetics, clinical presentation, diagnosis and treatment. Blood Coagul Fibrinolysis 1990;1:319-30.

6. Gruber A, Mori E, del-Zoppo GJ, Waxman L, Griffin JH. Alteration of fibrin network by activated protein C. Blood 1994;83:2541-8. doi: http://dx.doi.org/.

7. Canhão P, Ferro JM, Lindgren AG, Bousser MG, Stam J, Barinagarrementeria F, et al. Causes and predictors of death in cerebral venous thrombosis. Stroke 2005; 36:1720. doi: 10.1161/01.STR.0000173152.84438.

8. Borhani Haghighi A, Edgell RC, Cruz-Flores $\mathrm{S}$, Feen E, Piriyawat $\mathrm{P}$, Vora $\mathrm{N}$, et al. Mortality of cerebral venous-sinus thrombosis in a large national sample. Stroke 2012; 43:262. doi:

doi:

10.1161/STROKEAHA.111.635664.

9. Kenet G, Kirkham F, Niederstadt T, Heinecke A, Saunders D, Stoll M, et al. Risk factors for recurrent venous thromboembolism in the European collaborative paediatric database on cerebral venous thrombosis: a multicentre cohort study. Lancet Neurol 2007; 6:595. doi: 10.1016/S1474-4422(07)70131-X.

10. Diaz JM, Schiffman JS, Urban ES, Maccario M. Superior sagittal sinus thrombosis and pulmonary embolism: a syndrome rediscovered. Acta Neurol Scand 1992; $86: 390$.

11. Crassard, I, Canhão, P, Ferro, JM, Bousser MG, Barinagarrementeria F, Stam J. Neurological worsening in the acute phase of cerebral venous thrombosis in ISCVT (International Study on Cerebral Venous Thrombosis). Cerebrovasc Dis 2003; 16 Supp 4:60

12. Starn J. Thrombosis of the cerebral veins and sinuses. N Engl J Med 2005;352:1791-8. doi: 10.1056/NEJMra042354.

13. Rondepierre P, Hamon M, Leys D, Leclerc X, Mounier-Vehier F, Godefroy $\mathrm{O}$, et al. [Cerebral venous thromboses: study of the course]. Rev Neurol (Paris) 1995; 151:100.

14. Preter M, Tzourio C, Ameri A, Bousser MG. Long-term prognosis in cerebral venous thrombosis. Follow-up of 77 patients. Stroke 1996; 27:243. doi: 10.1161/01.STR.27.2.243.

15. Nagesh Kumar TC, Kenchappa R, Kempegowda MB, Kulkarni A. Protein $\mathrm{S}$ 
deficiency in a case of superor sagital vein thrombosis. Indian J Med Sci 2011;65:36-9. doi: 10.4103/0019-5359.103170.

16. Marcos LA, Majid R, Hamzeh N, Mehta N, Escobar M. An acute intracerebral vein thromboses in AIDS with protein $\mathrm{C}$ and $\mathrm{S}$ deficiency. Int J STD AIDS 2008;19:59-61. doi: 10.1258/ijsa.2007.007145.

17. Kuwahara S, Abe T, Uga S, Mori K. Superior sagittal sinus and cerebral cortical venous thrombosis caused by congenital protein $\mathrm{C}$ deficiency-case report. Neurol Med Chir (Tokyo) 2000;40:645-9. doi.org/10.2176/nmc.40.645.

18. Singhal AB, Buonanno F, Rordorf G. Cerebral venous sinus thrombosis associated with hepatic cirrhosis. J Neurol Sci 1999;171:65-8.

19. Lefebvre P, Lierneux B, Lenaerts L, Van Maldergem L, Marecaux G, Daune M. Cerebral venous thrombosis and procoagulant factors-a case study. Angiology 1998;49:56371. doi: 10.1177/000331979804900707.

20. Roos KL, Pascuzzi RM, Kuharik MA, Shapiro AD, Manco-Johnson MJ. Postpartum intracranial venous thrombosis associated with dysfunctional protein $\mathrm{C}$ and deficiency of protein S. Obstet Gynecol 1990;76(3 Pt 2):492-4.

21. Massons J, Arboix A, Oliveres M, Besses C, Muñoz C, Titus F. Cerebral venous thrombosis and hereditary protein $\mathrm{C}$ deficiency. Neurologia 1992;7:34-8.

22. Chung BH, Ma ES, Khong PL, Chan GC. Inherited thrombophilic factors do not increase central venous catheter blockage in children with malignancy. Pediatr Blood
Cancer
2008;51:509-12.
doi:
10.1002/pbc. 21617.

23. Barker M, Thoenes D, Döhmen H, Friedrichs F, Pfannenstiel C, Heimann G. Prevalence of thrombophilia and catheter-related thrombosis in cystic fibrosis. Pediatr Pulmonol 2005;39:156-61.

doi: DOI: $10.1002 / \mathrm{ppul} .20158$.

24. Nowak-Göttl U, Dübbers A, Kececioglu D, Koch HG, Kotthoff S, Runde J, et al. Factor V Leiden, protein $\mathrm{C}$, and lipoprotein (a) in catheter-related thrombosis in childhood: a prospective study. J Pediatr 1997;131:608-12.

25. Wermes C, von Depka Prondzinski M, Lichtinghagen R, Barthels M, Welte K, Sykora KW. Clinical relevance of genetic risk factors for thrombosis in paediatric oncology patients with central venous catheters. Eur $J$ Pediatr 1999;158 Suppl 3:S143-6.

26. Ferro JM, Canhao P, Stam J, Bousser MG, Barinagarrementeria F. Prognosis of cerebral vein and dural sinus thrombosis: results of the International Study on Cerebral Vein and Dural Sinus Thrombosis (ISCVT). Stroke 2004;35:664-670. doi: 10.1161/01.STR.0000117571.76197.

27. Poon CS, Chang JK, Swarnkar A, Johnson $\mathrm{MH}$, Wasenko J. Radiologic diagnosis of cerebral venous thrombosis: pictorial review. Am J Radiol 2007;189:S64-S75.

28. Karthikeyan D, Vijay S, Kumar T, Kanth L. Cerebral venous thrombosis-spectrum of CT findings. Neuroradiology 2004;14:129-37. http://www.ijri.org/text.asp?2004/14/2/129/28 567. 